\title{
PERBANDINGAN KEMAMPUAN KONEKSI MATEMATIS SISWA MELALUI MODEL PEMBELAJARAN CONECTING ORGANIZING REFLECTING EXTENDING (CORE) DENGAN MODEL PEMBELAJARAN KONVENSIONAL DI KELAS VIII SMP NEGERI 15 KOTA JAMBI
}

\author{
Anggara Novia Noka Saputra ${ }^{1}$, Hasan Basri Said ${ }^{2}$, Eni Defitriani $^{3}$ \\ Program Studi Pendidikan Matematika, FKIP, Universitas Batanghari ${ }^{1,2,3}$ \\ Jl. Slamet Riyadi No.1 Broni Jambi \\ e-mail: love_jambi@yahoo.co.id
}

\begin{abstract}
ABSTRAK
Penelitian ini bertujuan untuk mengetahui perbandingan kemampuan koneksi matematis siswa antara yang diajarkan dengan menggunakan model pembelajaran Conecting Organizing Reflecting Extending (CORE) dan model pembelajaran konvensional. Penelitian ini merupakan penelitian eksperimen dengan rancangan penelitian menggunakan desain eksperimen Posttest Only Control Design. Populasi dalam penelitian ini adalah seluruh siswa kelas VIII SMP Negeri 15 Kota Jambi yang terdiri dari delapan kelas. Sedangkan sampelnya adalah siswa kelas VIII D sebagai kelas eksperimen dan kelas VIII H sebagai kelas kontrol yang diambil secara random sampling. Teknik analisis data menggunakan Uji t. Hasil diperoleh dari hasil analisis data yang dilakukan pada dua sampel diperoleh nilai rata-rata kemampuan koneksi matematis kelas eksperimen 16,43 dengan simpangan baku 11,94 dan nilai rata-rata kemampuan koneksi matematis kelas kontrol 14,28 dengan simpangan baku 11,93, serta hasil uji hipotesis diperoleh $t_{\text {hitung }} 2,32$ dan $t_{\text {tabel }}$ 1,67 pada taraf nyata $\alpha$ yaitu 0,05 . Dari hasil perhitungan tersebut terlihat bahwa $t_{\text {hitung }}$ lebih besar dari $\mathrm{t}_{\text {tabel }}$, maka $\mathrm{H}_{0}$ ditolak dan $\mathrm{H}_{1}$ diterima. Berdasarkan hasil akhir dapat disimpulkan bahwa kemampuan koneksi matematis siswa yang diajarkan dengan menggunakan model pembelajaran Conecting Organizing Reflecting Extending (CORE) lebih tinggi dari pada kemampuan koneksi matematis siswa yang diajarkan dengan menggunakan model pembelajaran konvensional.
\end{abstract}

Kata kunci :

Kemampuan Koneksi Matematis, Model Pembelajaran Conecting Organizing Reflecting Extending (CORE), Model Pembelajaran Konvensional.

\begin{abstract}
This study aims to determine the comparison of students' mathematical connection abilities between those taught using the Conecting Organizing Reflecting Extending (CORE) learning model and conventional learning models. This research is an experimental research study design using the Posttest Only Control Design experimental design. The population in this study were all eighth grade students of SMP Negeri 15 Jambi City which consisted of eight classes. While the sample is students of class VIII D as the experimental class and class VIII $H$ as the control class taken by random sampling. Data analysis techniques using the t test. The results obtained from the results of data analysis conducted on the two samples obtained the average value of the ability of mathematical connection experimental class 16.43 with standard deviation of 11.94 and the average value of mathematical connection ability of control class 14.28 with standard deviation of 11.93, and the results of hypothesis testing obtained tcount 2.32 and ttable 1.67 at the significance level $\alpha$ that is 0.05. From the results of these calculations it can be seen that $t$ count is greater than t_table, then $H_{-} O$ is rejected and $H_{-} l$ is accepted. Based on the final results it can be concluded that the mathematical connection ability of students taught using the Conecting Organizing Reflecting Extending (CORE) learning model is higher than the mathematical connection ability of students taught using conventional learning models.
\end{abstract}

Keywords :

Mathematical Connection Capabilities, Conecting Organizing Reflecting Extending (CORE) Learning Models, Conventional Learning Models. 


\section{$\pi$ (Phi)}

\section{PENDAHULUAN}

Pembelajaran matematika adalah suatu proses belajar mengajar yang dibangun oleh guru untuk menggembangkan kreativitas berpikir siswa yang dapat meningkatkan kemampuan berpikir matematis siswa. Salah satu kemampuan matematis yang perlu dimiliki siswa adalah kemampuan koneksi matematis.

Kemampuan koneksi merupakan kemampuan siswa dalam mengoneksikan keterkaitan antar topik matematika dan dalam mengoneksikan antara dunia nyata dan matematika. Menurut Defitriani (2018) matematika harus dipadankan dengan keilmuan bidang lain dalam kehidupan sehari-hari agar lebih bermakna. membantu siswa untuk memperluas perspektifnya, memandang matematika sebagai suatu bagian yang terintegrasi daripada sekumpulan topik, serta mengenal adanya relevansi dan aplikasi di dalam kelas maupun di luar kelas.

Fakta yang diperoleh di lapangan saat ini menunjukkan bahwa kemampuan koneksi matematis siswa masih rendah. Dilihat dari siswa mengalami kesulitan dalam menyelesaikan soal yang diberikan guru. Salah satu faktor lain yang mempengaruhi perkembangan kemampuan koneksi siswa adalah suasana kelas yang kurag interaktif. Pengunaan model pembelajaran yang kurang tepat sehingga membuat proses belajar menjadi monoton dan mempengaruhi kemampuan koneksi matematis siswa.

Berdasarkan hasil observasi di SMP Negeri 15 Kota Jambi untuk kelas VIII dalam proses pembelajaran di kelas dengan salah satu guru matematika mengatakan bahwa kemampuan koneksi matematis siswa masih rendah. Dalam proses pembelajaran guru menggunakan model pembelajaran konvensional. Model pembelajaran konvensional merupakan model pembelajaran yang mengacu pada gaya mengajar dimana guru terlibat aktif dalam mengusung isi pelajaran kepada peserta didik dan mengajarkan secara langsung kepada seluruh kelas. Sehingga membuat siswa kurang berpartisipasi dalam proses pembelajaran.

Mengacu pada permasalahan di atas, guru perlu melatih dan meningkatkan kemampuan koneksi matematis siswa. Salah satu upaya untuk meningkatkan kemampuan koneksi matematis siswa dengan menggunakan model pembelajaran yang inovatif seperti model pembelajaran Conecting Organizing Reflecting Extending (CORE).

Artikel ini membahas hasil penelitian terkait implementasi model pembelajaran Conecting Organizing Reflecting Extending (CORE). Lebih lanjut dideskripsikan apakah terdapat perbedaan kemampuan koneksi matematis siswa yang dibelajarkan dengan model pembelajaran Conecting Organizing Reflecting Extending (CORE) jika dibandingkan dengan menggunakan model pembelajaran konvensional.

Model pembelajaran Conecting Organizing Reflecting Extending (CORE) adalah model pembelajaran yang menekankan pada kemampuan berpikir siswa untuk menghubungkan, mengorganisasikan, mendalami, mengelola, dan mengembangkan informasi yang didapat. Menurut Calfee, et al (Dwijayanti dan Kurniasih, 2014) model Conecting Organizing Reflecting Extending (CORE) adalah suatu model pembelajaran yang mengharapkan siswa untuk dapat mengkonstruksi pengetahuannya sendiri, dengan cara menghubungkan (connecting) dan mengorganisasikan (organizing) pengetahuan baru dengan pengetahuan lama, kemudian memikirkan konsep yang sedang dipelajari (reflecting), serta diharapkan siswa dapat memperluas pengetahuan mereka selama proses belajar mengajar berlangsung (extending).

Dari uraian di atas dapat disimpulkan bahwa pembelajaran Conecting Organizing Reflecting Extending (CORE) adalah model pembelajaran yang menekankan 


\section{$\pi$ (Phi)}

kemampuan berpikir siswa untuk menghubungkan, mengorganisasikan, mendalami, mengelola, dan mengembangkan informasi yang didapatnya.

Model pembelajaran konvensional adalah model pembelajaran yang menempatkan guru sebagai sumber belajar. Pembelajaran konvensional merupakan pembelajaran biasa yang paling sering dilakukan oleh guru-guru disekolah. Pada pembelajaran ini guru memberikan penerangan atau penuturan secara lisan kepada sejumlah siswa. Siswa mendengarkan dan mencatat seperlunya. Pada umumnya siswa bersifat pasif karena hanya menerima apa saja yang dijelaskan oleh guru.

Kemampuan koneksi matematis merupakan kemampuan mengaitkan konsepkonsep matematika baik antar konsep matematika itu sendiri (dalam matematika) maupun mengaitkan konsep matematika dengan bidang lainnya (luar matematika).

Pemahaman siswa akan lebih mendalam jika siswa dapat mengkaitkan antar konsep yang telah diketahui siswa dengan konsep baru yang akan dipelajari siswa. Seseorang akan lebih mudah mempelajari sesuatu apabila belajar itu didasari kepada apa yang telah diketahui orang tersebut. Oleh karena itu, untuk mempelajari suatu materi matematika yang baru pengalaman belajar yang lalu dari seseorang itu akan mempengaruhi terjadi proses belajar materi matematika tersebut.

\section{METODE PENELITIAN}

Jenis penelitian ini merupakan penelitian eksperimen. Menurut Sugiyono (2012) metode penelitian eksperimen dapat diartikan sebagai metode penelitian yang digunakan untuk mencari pengaruh perlakuan tertentu terhadap yang lain dalam kondisi yang terkendalikan. Populasi dalam penelitian ini adalah seluruh siswa kelas VIII SMP Negeri 15 Kota Jambi tahun ajaran 2017/2018, sebanyak 216 siswa yang terdistribusi dalam delapan kelas (VIII A,

VIII B, VIII C, VIII D, VIII E, VIII F, VIII G, VIII H). Pengambilan sampel dalam penelitian ini dengan teknik random sampling. Pemilihan kelas eksperimen dan kelas kontrol digunakan secara undian, yang terpilih pertama sebagai kelas eksperimen yaitu kelas VIII D dengan model pembelajaran Conecting, Organizing, Reflecting, Extending (CORE) dan yang terpilih kedua adalah kelas kontrol yaitu kelas VIII $\mathrm{H}$ dengan model pembelajaran Konvensional.

Rancangan penelitian dalam penelitian ini menggunakan desain eksperimen Posttest Only Control Design. Rancangan penelitiannya sebagai berikut:

Tabel 1. Rancangan Penelitian

\begin{tabular}{|lll|}
\hline $\mathbf{R}$ & $\mathbf{X}$ & $\mathbf{O}_{1}$ \\
$\mathbf{R}$ & & $\mathbf{O}_{2}$ \\
\hline
\end{tabular}

\section{HASIL DAN PEMBAHASAN}

Hasil penelitian yang disajikan dalam penelitian ini ada dua bagian, yaitu hasil penelitian yang diperoleh melalui analisis statistik deskriptif dan analisis statistik inferensial. Analisis statistik deskriptif yang disajikan meliputi ukuran sampel, nilai ratarata, nilai tertinggi, nilai terendah, simpangan baku, dan varians. Sedangkan analisis inferensial meliputi hasil uji-t.

Tabel 2. Karakteristik Nilai dari Hasil Post-Test

Kemampuan Koneksi Matematis Siswa

\begin{tabular}{ccc}
\hline Statistika & $\begin{array}{c}\text { Kelas } \\
\text { Eksperimen }\end{array}$ & $\begin{array}{c}\text { Kelas } \\
\text { Kontrol }\end{array}$ \\
\hline Ukuran Sampel & 28 & 28 \\
Rata-rata & 15,14 & 13,14 \\
Nilai Tertinggi & 19 & 17 \\
Nilai Terendah & 8 & 6 \\
Simpangan Baku & 3,08 & 3,03 \\
Varians & 9,49 & 9,20 \\
\hline
\end{tabular}

Berdasarkan tabel di atas dapat dilihat bahwa jumlah siswa kelas eksperimen adalah 28 siswa dan kelas kontrol sebanyak 28 siswa. Rata-rata skor kemampuan koneksi matematis siswa dikelas eksperimen adalah 15,14 dengan skor tertinggi 19 dan skor terendah 8. Simpangan baku kelas eksperimen adalah 3,08 sehingga varians sebesar 9,49. Sedangkan rata-rata skor 
kemampuan koneksi matematis siswa dikelas kontrol adalah 13,14 dengan skor tertinggi 17 dan skor terendah 6. Simpangan baku kelas kontrol adalah 3,03 sehingga varians sebesar 9,20. Sehingga dapat disimpulkan bahwa rata-rata kemampuan koneksi matematis siswa yang diajarkan dengan menggunakan model pembelajaran Conecting Organizing Reflecting Extending (CORE) lebih tinggi dari pada rata-rata kemampuan koneksi matematis siswa yang diajarkan dengan menggunakan model pembelajaran konvensional.

Pengujian prasyarat dilakukan sebelum pengujian hipotesis. Data yang akan dianalisis merupakan data tes kemampuan koneksi matematis siswa yang melalui pembelajaran dengan model pembelajaran Conecting Organizing Reflecting Extending (CORE). Uji prasyarat yang dilakukan adalah uji normalitas dan uji homogenitas.

Tabel 3. Uji Normalitas Post-Test

\begin{tabular}{cccccc}
\hline Kelas Sampel & $\mathrm{N}$ & $\chi_{\text {hitung }}^{2}$ & $\chi_{\text {tabel }}^{2}$ & Kriteria Pengujian & Keterangan \\
\hline Eksperimen & 28 & 7,18 & 7,81 & $\chi_{\text {hitung }}^{2}<\chi_{\text {tabel }}^{2}$ & Normal \\
Kontrol & 28 & 5,48 & 7,81 & $x^{2}$ & \\
\hline
\end{tabular}

Berdasarkan tabel 3 di atas, dapat dilihat bahwa uji normalitas kemampuan koneksi matematis siswa kelas eksperimen mempunyai nilai $x^{2}{ }_{\text {hitung }}$ sebesar 7,18 lebih kecil dari pada $x^{2}$ tabel sebesar 7,81. Dikelas kontrol kemampuan koneksi matematis

Tabel 4. Uji Homogenitas Post-Test

\begin{tabular}{|c|c|c|c|c|c|}
\hline \multicolumn{2}{|c|}{ Varians } & \multirow[t]{2}{*}{$\alpha$} & \multirow{2}{*}{$F_{\text {hitung }}$} & \multirow[t]{2}{*}{$F_{\text {tabel }}$} & \multirow[t]{2}{*}{ Keterangan } \\
\hline Eksperimen & Kontrol & & & & \\
\hline 9,49 & 9,20 & $5 \%$ & 1,02 & 1,88 & Homogen \\
\hline
\end{tabular}
bahwa uji homogenitas post-test menghasilkan $F_{\text {hitung }}$ sebesar 1,02 dan $F_{\text {tabel }}$ sebesar 1,88 . Oleh karena nilai $F_{\text {hitung }}$ lebih kecil dari pada $F_{\text {tabel }}$ maka dapat disimpulkan bahwa kelas eksperimen dan kelas kontrol memiliki varians yang homogen.

Teknik statistik yang digunakan untuk menguji hipotesis menggunakan uji-t. Dari perhitungan diperoleh nilai $t_{\text {hitung }}$ sebesar 2,43 dan $t_{\text {tabel }}$ sebesar 1,67. Kriteria pengujian: jika $t_{\text {hitung }}$ lebih kecil dari pada $t_{\text {tabel }}$ maka $H_{0}$ ditolak. Karena nilai $t_{\text {hitung }}$ lebih besar dari pada $t_{\text {tabel }}$ maka $H_{0}$ ditolak dan $H_{1}$ diterima. Jadi, dapat disimpulkan bahwa rata-rata kemampuan koneksi matematis siswa yang diajarkan menggunakan model pembelajaran Conecting Organizing Reflecting Extending (CORE) lebih tinggi dari pada yang dibelajarkan dengan menggunakan model pembelajaran konvensional. siswa mempunyai nilai $x^{2}{ }_{\text {hitung }}$ sebesar 5,48 lebih kecil dari pada $x^{2}{ }_{\text {tabel }}$ sebesar 7,81. Dapat diartikan bahwa kelas eksperimen dan kelas kontrol berdistribusi normal. eksperimen, penulis menggunakan model pembelajaran Conecting Organizing Reflecting Extending (CORE) kepada siswa dalam melakukan pembelajaran materi persamaan relasi dan fungsi. Siswa dituntut aktif dalam memahami materi. Siswa di kelas eksperimen ini mempelajari materi disertai dengan kegiatan praktek. Dalam model pembelajaran Conecting Organizing Reflecting Extending (CORE) siswa dikelompokkan kedalam beberapa kelompok yang terdiri dari 4-5 siswa dengan kemampuan siswa yang heterogen dan saling bertukar pikiran satu sama lain.

Pada pertemuan pertama siswa diberikan soal untuk diamati dan melatih siswa untuk menemukan sendiri penyelesaian mengenai bentuk penyajian relasi. Siswa dalam kelompok dibimbing untuk dapat memahami pembelajaran dengan adanya kegiatan pengamatan. Pada pertemuan kedua siswa diminta untuk 


\section{$\pi$ (Phi)}

menentukan yang merupakan fungsi dan bukan fungsi. Begitu seterusnya sampai pertemuan keempat.

Selama proses pembelajaran di kelas eksperimen berlangsung siswa terlihat aktif dan memiliki rasa ingin tahu yang tinggi terhadap materi yang disampaikan. Siswa diikutsertakan dalam kegiatan praktek seperti menggambar dan sebagainya. Sehingga suasana kelas tidak kaku, proses pembelajaran lebih asik dan kreatif. Selanjutnya, kemampuan koneksi matematis siswa di kelas eksperimen terbukti lebih tinggi. Hal ini dapat dilihat pada pelaksanaan post-test. Siswa kelas eksperimen mampu mengerjakan soal dengan benar dan tepat. Sehingga nilai rata-rata dari keseluruhan siswa di kelas eksperimen memperoleh angka yang memuaskan.

Berbeda dengan kelas eksperimen, kelas kontrol diajarkan dengan model pembelajaran konvensional. Selama proses pembelajaran siswa diajarkan dengan metode ceramah. Dengan bantuan buku paket yang diberikan kepada siswa, siswa memahami lalu mengerjakan soal-soal dalam buku tersebut. Proses pembelajaran dalam kelas kontrol lebih monoton. Penulis mengajarkan materi hanya satu arah. Sedikit sekali siswa yang memiliki minat untuk memberikan umpan balik atas materi yang disampaikan. Dengan demikian guru kembali menerangkan materi yang sama. Sehingga proses pembelajaran yang diajarkan di kelas kontrol kurang efektif dan efisien.

\section{SIMPULAN DAN SARAN}

Berdasarkan hasil penelitian dapat disimpulkan bahwa nilai simpangan baku diperoleh 3,08 dan 3,03. Pengujian dilakukan dengan uji-t dan diperoleh nilai $t_{\text {hitung }}$ sebesar 2,43 dan $t_{\text {tabel }}$ sebesar 1,67. Terlihat nilai $t_{\text {hitung }}$ lebih besar dari $t_{\text {tabel }}$ maka $H_{0}$ ditolak dan $H_{1}$ diterima. Hal ini menunjukkan bahwa kemampuan koneksi matematis siswa yang diajarkan dengan menggunakan model pembelajaran Conecting Organizing Reflecting Extending (CORE) lebih tinggi dari pada kemampuan koneksi matematis siswa yang diajarkan dengan menggunakan model pembelajaran konvensional.

Berdasarkan kesimpulan dapat penulis kemukakan saran sebagai berikut:

1. Guru diharapkan dapat menggunakan Model Pembelajaran Conecting Organizing Reflecting Extenting (CORE) sebagai salah satu cara untuk meningkatkan keaktifan dan motivasi siswa dalam belajar.

2. Diharapkan bagi siswa agar lebih giat dan aktif dalam mengikuti proses pembelajaran matematika khususnya pada kelas VIII.

3. Bagi peneliti selanjutnya yang ingin melanjutkan penelitian ini diharapkan untuk lebih meluangkan waktu khusus untuk menjelaskan model pembelajaran Conecting Organizing Reflecting Extenting (CORE) kepada siswa supaya siswa termotivasi dalam proses pembelajaran.

\section{DAFTAR PUSTAKA}

Defitriani, Eni. (2018). Mengembangkan Kemampuan Koneksi Matematis Melalui Pendekatan Differentiated Instruction. ANARGYA:Jurnal Ilmiah Pendidikan Matematika Vol 1 No 2

Dwijayanti, Kurniasih. (2014). Ragam Pengembangan Model Pembelajaran. Surakarta: FKIP UMS.

Sugiyono. (2012). Motode Penelitian Kuantitatif, Kualitatif, dan $R \& D$. Bandung: Alfabeta 